\title{
INNOVATION AND SIMULATION-BASED TEACHING TECHNIQUE IN PATHOLOGICAL PHYSIOLOGY
}

\author{
Lea Kováčiková ${ }^{1}$, Ferdinand Varga ${ }^{2}$, Eva Kvaltínyová ${ }^{3}$, Jana Plevková ${ }^{4}$, Tomáš Buday ${ }^{5}$
}

\begin{abstract}
Simulation-based learning in medicine has gained substantial importance. It is complementary to often limited clinical practice, and helps interconnect theoretical knowledge with practical training. Simulations are implicated in clinical subjects, but based on recent understanding, simulation can also be used in preclinical subjects, where it can support presented tasks. Simulation technology was used for elective practical sessions in a pathophysiology course, with both measurable outcomes and students' feedback evaluated. This study was conducted in Slovakia with volunteers $(n=22)$, who were 3rd-year students of General Medicine (simulation group), paired with classmates in traditional seminars (control group; $n=22$ ) with the same achievement grades. The control group had completed traditional seminars, whereas the simulation group had completed simulationbased seminars in cardiovascular pathophysiology. A standardized student feedback survey, visual analogue scale, and credit tests for regular pathophysiology were used to perform the analysis. Subjective feedback suggested positive outcomes in approximately $80 \%$ of students. An objective assessment showed that simulation-based seminars did not increase the theoretical knowledge as documented by 1 st credit test ( simulation vs control; $42 \pm 6$ vs $41 \pm 4 ;$ p > 0.05), but rather their approach to clinical application of obtained information and motivation to study.
\end{abstract}

UDC Classification: 616.1 DOI: http://dx.doi.org/10.12955/cbup.v4.840

Keywords: simulation-based learning, education, pathophysiology, innovative learning.

\section{Introduction}

In pre-graduate medical studies, the use of simulation technologies follows the most up-to-date trends in education of doctors and other healthcare professionals (Wang, Liu, \& Wang, 2013). In simulationbased learning, various animations, 3-dimensional atlases, interactive clinical tutorials with virtual patients' case reports, numerous models, computer-operated high-fidelity patient simulators, and standardized patients are available. Some of these technologies are available at Jessenius Faculty of Medicine, Comenius University (JFMED CU), in Martin, Slovakia.

The main goal for using simulation technologies is to connect theoretical knowledge with practical skills; in clinical disciplines it is mainly repetition of therapeutic or diagnostic procedures. Medical faculties using simulation technologies have documented positive influence on learning outcomes (Harris, Ryan, \& Rabuck, 2012; Wood, 2003).

Simulation technologies are primarily used in teaching of clinical disciplines, such as internal medicine, emergency medicine, pediatrics, pediatric intensive care, gynecology, and obstetrics and anesthesiology (Bhattacharya, Shankar, Khaliq, Rajesh, \& Tandon, 2005). According to the latest knowledge, simulation technologies can also be used in pre-clinical and theoretical disciplines, where they support theoretical knowledge and demonstrate possible clinical applications (Kovac, 2007; Hanacek, 2001; Mierson, 1998).

At the 2013 Conference of the Association for Medical Education in Europe (AMEE) in Prague, a poster presentation of a study showed the possibilities of using simulation technologies in chosen Pathological Physiology courses. At the time, only a subjective evaluation by students was available from a general feedback questionnaire. During the presentation and discussion to this work, those

\footnotetext{
${ }^{1}$ Lea Kováčiková, Simulation Education Center \& Department of Pathophysiology, Jessenius Faculty of Medicine in Martin, Comenius University, lea.kovacikova@gmail.com

${ }^{2}$ Ferdinand Varga, Simulation Education Center, Jessenius Faculty of Medicine in Martin, Comenius University, varga@jfmed.uniba.sk

${ }^{3}$ Eva Kvaltínyová, Simulation Education Center, Jessenius Faculty of Medicine in Martin, Comenius University, kvaltinyova@jfmed.uniba.sk

${ }^{4}$ Jana Plevková, Simulation Education Center \& Department of Pathophysiology, Jessenius Faculty of Medicine in Martin, Comenius University, plevkova@jfmed.uniba.sk

5 Tomáš Buday, Simulation Education Center \& Department of Pathophysiology, Jessenius Faculty of Medicine in Martin, Comenius University, buday@jfmed.uniba.sk
} 
present in the auditorium agreed on the importance of an objective assessment, where the request to obtain measurable outcomes of efficacy for teaching Pathological Physiology using simulation technologies was derived.

The main aims of this study are to obtain objective parameters for the efficacy of simulation-based learning (SBL) in Pathological Physiology and to quantify a subjective assessment using visual analogue scale (VAS), so that the outcomes could be compared with data published in literature relating to theory of medical education.

\section{Methods}

To obtain objective data, the study comprised 22 volunteer 3rd-year students of General Medicine (simulation group), who were informed about the aims and course of the project and had joined four seminars at the Simulation Education Center, JFMED CU. These seminars were oriented on pathophysiology of the cardiovascular system.

In addition, a randomly chosen group was formed of 3rd-year students (control group) who attended the same school as the simulation group, but joined in traditional seminars for Pathological Physiology at JFMED CU. A condition of this group was that each student had the same achievement grade in the winter semester as a paired student in the simulation group. The aim was not for both groups to have the same average grade, but for each simulation student to have 'their own' control, that is, matched with a student with the same grade in the control group.

For one objective outcome, we used results of students' 1st credit test for the pathophysiology of cardiovascular system from the 7th week of the summer semester. Other sources of information were a VAS evaluation for intelligibility of the lecture, an understanding of relationship sign (symptom) as a mechanism, chance of future clinical application, self-reported confidence, and the capacity to stay focused during whole seminar.

The last sources of data were the results from the general feedback provided in a questionnaire available on the Simulation Center web page.

The content of the simulation seminars included topics of dysrhythmias, cardiac failure, valvular heart diseases, and disturbances of circulation in lower extremities. These were consistent with topics taught in the traditional way in the first half of the summer semester of the teaching for Pathological Physiology.

\section{Results}

The chosen seminars were conducted in a manner known in literature as problem-based learning, and the second method was guided learning. Seminars consistently had the same structure with a brief explanation of the theoretical background, case reports, analysis, and a short simulation followed by debriefing. Simulation technologies used in the seminars were METIMan ${ }^{\circledR}$ Prehospital with its operating software, Muse, which can simulate changes of different physiological parameters; and Harvey ${ }^{\circledR}$, a cardiopulmonary auscultation simulator, more suitable for demonstrating valvular heart diseases, and its software, UMedic, containing various case reports relating to the topic.

The assessment of teaching with point scores in credit tests can indicate a wide range of knowledge. The result of the 1 st test were medians of 42 points $( \pm 6)$ in the simulator based learning (SBL) group, and 41 points $( \pm 4)$ in the control group. There were no statistical differences between these group in the scores $(\mathrm{p}>0.05)$, with both groups satisfactorily passing the test. Based on this outcome, the tested simulation group did not show an 'advantage' in their pool of knowledge over the control group (Figure 1).

Although the VAS assessment is subjective, it is often used to quantify parameters which cannot be measured objectively (e.g., pain or dyspnea). The VAS is also used in the evaluation of pedagogic process in various forms. Results show that there was a significant difference in all aspects: intelligibility, understanding of pathomechanisms and their importance in potential clinical applications, self-reported confidence, and understanding; difference was also found in the ability to stay focused throughout whole seminar (Figure 2). 
Figure 1: Results of 1st credit test (scores) for simulator based learning (SBL) and 'traditional' groups

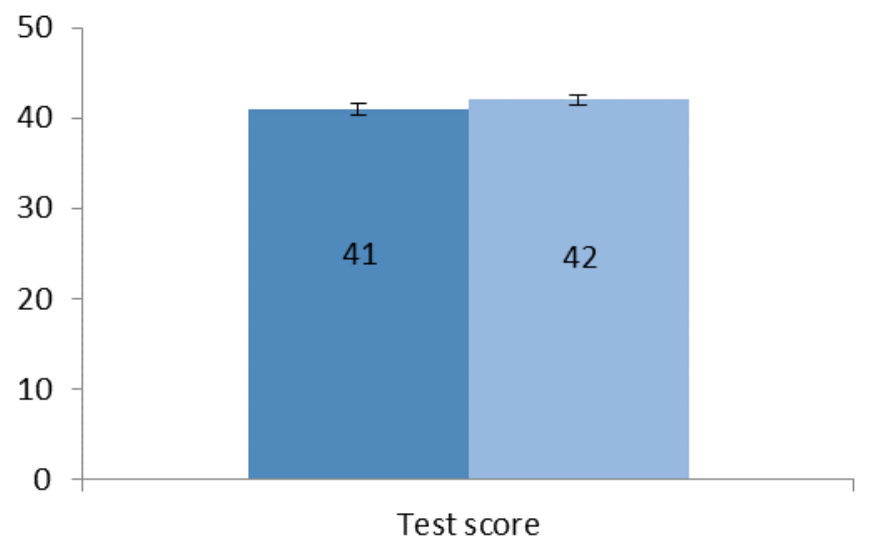

Traditonal seminar $\quad$ SBL seminar

Source: Authors

Figure 2: Results of visual analogue scale assessment (scores) for pedagogic process

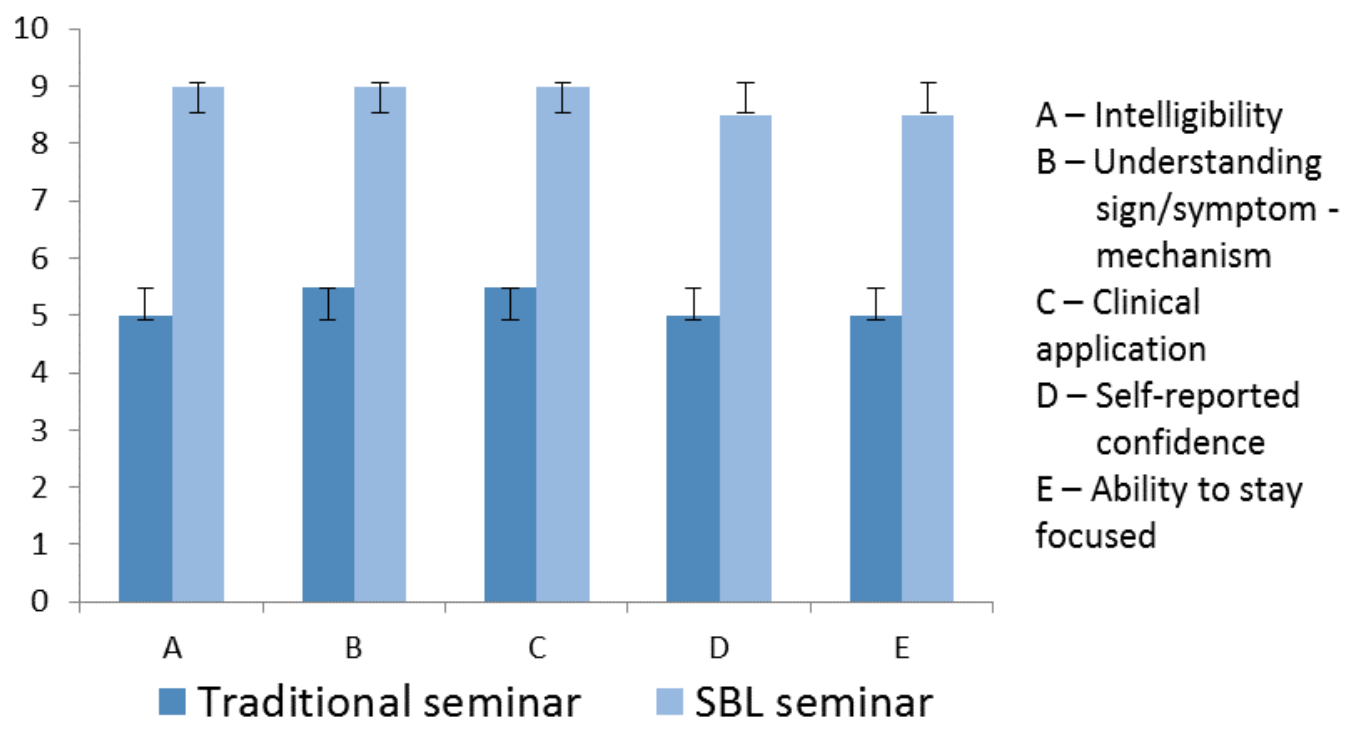

Source: Authors

Results from general feedback on the teaching technique used with the simulation technologies revealed that the use of simulation technologies was regarded a significant asset by $64 \%$ of respondents, $23 \%$ considered it optimal, and $13 \%$ indicated there was opportunity for improvement in utilizing the simulation technologies for teaching (Figure 3).

\section{Discussion}

According to our results, and experience from direct teaching, simulation technologies are an asset in supporting the teaching of Pathological Physiology, although the use of this technology did not lead to significant difference in scores in the 1st credit test. Thus, the study did not verify that attending SBL seminars improved the pool of knowledge based on the displayed insignificance in differences in test 
scores between the groups. However, test results are influenced by several factors, including the quality of the students, including their motivation, self-study, and current condition, apart from the way in which the seminars are held (Berkel, Scherpbier, Hillen, \& Vleuten, 2010; Dent \& Harden, 2009).

Figure 3: Results of student's general feedback on the use of simulation technology

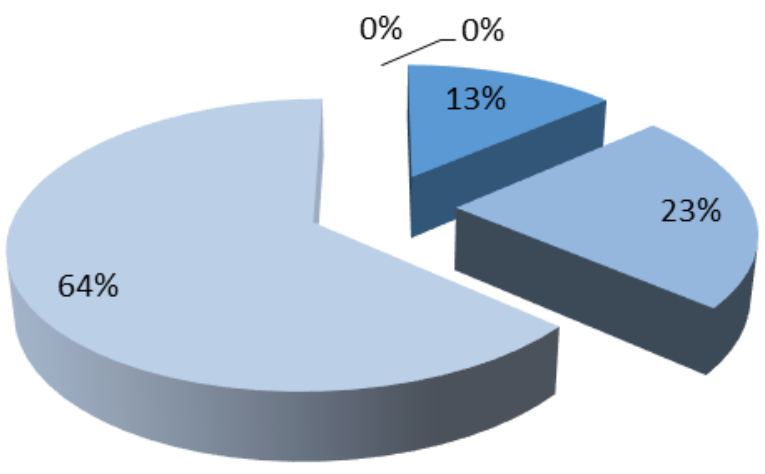

Significant asset: 64\%; Optimal value: 23\%; Opportunity for improvement: $13 \%$

Source: Authors

Figure 4: Photographs from seminars in the Simulation Center, Jessenius Faculty of Medicine, Comenius University
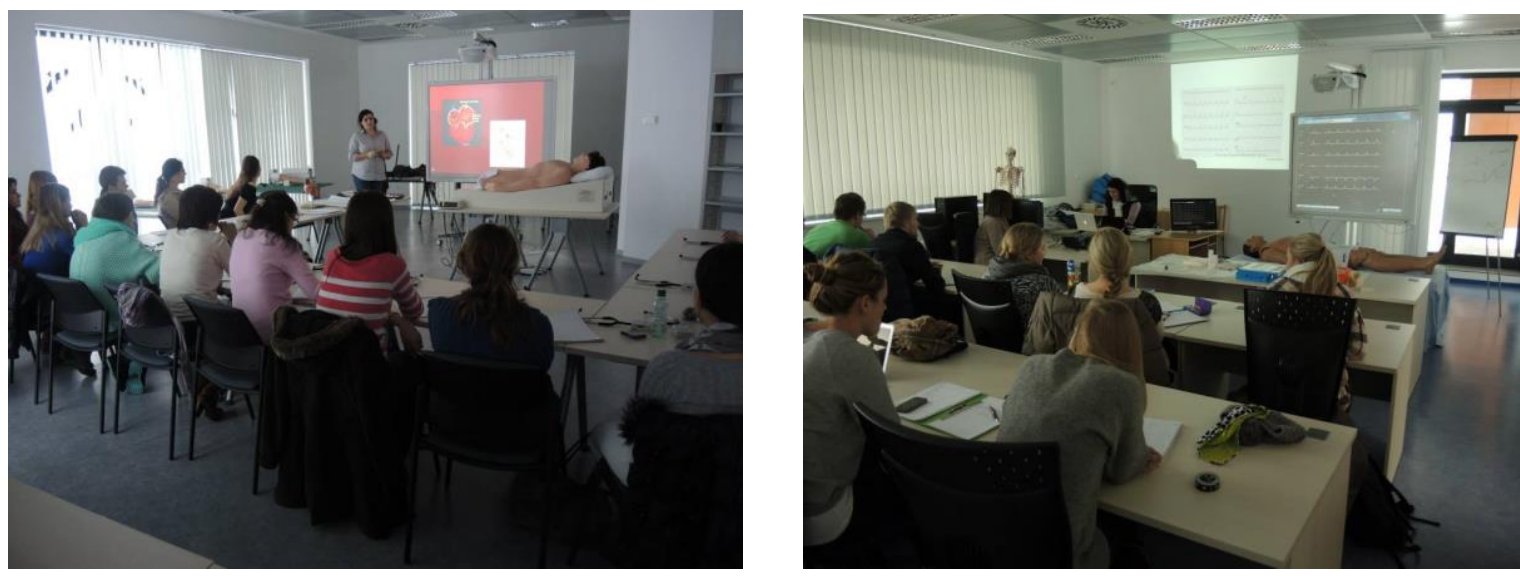

Source: Authors

Moreover, based on the subjective evaluation with the VAS, SBL seminars are important for intelligibility, understanding of relationship signs or symptoms as a mechanism, demonstration of clinical application, self-reported confidence, and capacity to stay focused.

\section{Conclusion}

These results show the potential for simulation technologies in the teaching of clinical disciplines, and the importance of repeated training in practical skills. While these types of seminars are attractive and valuable for students, based on this study's test results for Pathological Physiology they appear to be an extracurricular or optional way of teaching. 


\section{Acknowledgement}

This study was supported by the project: "Virtual and Simulation Tuition as a New Form of Education at JFMED CU in Martin" (ITMS: 26110230071), which was co-financed by the European Union.

\section{References}

Berkel, H. J., Scherpbier, A., Hillen, H. \& Vleuten, C. V. (2010). Lessons from problem-based learning. Oxford University Press.

Bhattacharya, N., Shankar, N., Khaliq, F., Rajesh, C. S., \& Tandon, O. P. (2005). Introducing problem-based learning in physiology in the conventional Indian medical curriculum. Natl Med J India, 18(2).

Dent, J. A. \& Harden, R. M. (2009). A practical guide for medical teachers. Edinburgh: Elsevier Churchill Livingstone. Hanacek, J. (2001). Undergraduate medical education in Slovakia--present state and future needs. Bratisl Lek Listy, 9, 438443.

Harris, D. M., Ryan, K., \& Rabuck, C. (2012). Using a high-fidelity patient simulator with first-year medical students to facilitate learning of cardiovascular function curves. Adv Physiol Educ, 36(3), 213-219. http://dx.doi.org/10.1152/advan.00058.2012

Kovac, Z. (2007). Beijing declaration on medical pathophysiology education. Adv Physiol Educ, 31(4), 387-388. http://dx.doi.org/10.1152/advan.00062.2007

Mierson, S. (1998). A problem-based learning course in physiology for undergraduate and graduate basic science students. Am J Physiol, 275, S16-S27.

Wang, Z., Liu, Q., \& Wang, H. (2013). Medical simulation-based education improves medicos' clinical skills. J Biomed Res, 27(2), 81-84. http://dx.doi.org/10.7555/JBR.27.20120131

Wood, D. F. (2003). Problem based learning. BMJ, 326(7384), 328. http://dx.doi.org/10.1136/bmj.326.7384.328 